\title{
Dental Caries Workshop Prevention Model for Primary Schools
}

\section{Najat Abdrabbo Alyafei*}

Pediatric Oncology Department, Mersin University, Qatar

*Corresponding Author: Najat Abdrabbo Alyafei, Mersin University, Mersin

University, Qatar.
Received: December 27, 2021

Published: January 31, 2022

(C) All rights are reserved by Najat Abdrabbo

Alyafei.

\section{Abstract}

Introduction: Dental caries, which is a form of dental infection, involves cavity formation or tooth destruction. In pre-primary and primary school children, dental caries prevalence is high under the circumstances of insufficient provision of awareness coupled with a decrease in interventional and preventive measures.

Methods: A total of eight participants attended the workshop, four each from a private school and a public school. The centre stage approach, based on diagrams with the most important item placed at the centre of the diagram, was used to obtain participants' view to co-produce the school oral health programme

Results: Schools, teachers, parents and pupils play a comprehensive, progressive and collaborative role in preventing the progression of dental caries, tooth destruction and any kind of dental infection. Behavioural affirmative strategies, workshops, awareness programmes and activities are altogether important in promoting oral health in children.

Conclusion: In order to reduce the prevalence of dental carries among school children, there is a need for a comprehensive school oral health policy with teachers and parents involved actively in its implementation.

Keywords: Dental Caries; Preventive Measures; Behavioural Strategies; Prevalence; Qatari Primary Schools

\section{Introduction}

Making the new generation more conscious of their actions in maintaining their oral hygiene, is the foremost theme and responsibility of the workshop arrangement. To guide the new generation by interacting with their parents, school teachers and the school clinic nurses in the most possible way is to raise the circumference of the awareness in the society. These enhancements in awareness roots protect humanity from various calamities at once. The backbone of the prevention model is to keep pupils healthy from dental caries and tooth destruction. The workshop was coproductive, and the final stage of the research where various links are interconnected among participants including parents, pupils and school nurses associated with time management and socioeconomic issues. Researchers evaluated the experienced-based results from public and private primary schools in Qatar. Consciously promoting oral hygiene at the level of private and public schools and homes helps to create a healthy environment. Parents and teachers work together to elevate the awareness in the growing children. A productive programme is always based on its long-lasting and fruitful future effects. Verbatim quotations from the participants and the visual technique of using centre stage diagrams drawn by the participants were used [1].

\section{Background in dental caries prevention}

The educational oral care preventive programme worked on the behavioural development in the children at a very early age, by its consequence, the children were deeply rooted upon these healthy behaviours. As a result, they were aware of dental hygiene to prevent oral caries formation [2]. Barriers in dental cleaning and hygiene reduced tremendously. This shows that the intervention 
model is of great importance in health care. The positive outcome of these interventions is to peddle back the gingivitis rate and dental caries formation. The usefulness and efficacy attained through the programme is quite higher than interpreted [2].

Researchers have also discussed in another research motive that the efficiency of these preventive workshops is much greater than expected. It has been declared by researchers researching Iranian participants that these trans-theoretical strategies were worthwhile in improving the cleaning and oral hygiene effectiveness in maintaining and developing the oral health care behaviours among children and parents [3]. The students after one year of counselling become more mindful of their dietary habits and less responsive towards behaviours that no more served healthy growth, the students have been moved from the contemplation stage to the somewhat contemplation stage [4].

\section{Dental caries outgrowth issues}

Universally, it is assessed that more than three million people were affected by oral health diseases including dental caries [5]. Approximately $35 \%$ of the total world population was affected by untreated dental caries, and the worldwide prevalence of periodontitis, dental caries and tooth loss were $11 \%$, 9\% and $2.5 \%$ respectively $[6,7]$. Dependent on Disability-Adjusted Life Years (DALYs) and Disability Lived Years, 224 years were lost per 100,000 population due to dental disease, and as a proportion of to DALYs for diseases, this rose from $0.6 \%$ to $20.8 \%$ between 2019 and 2020 respectively [7]. Workshops were designed to provide a platform for dentists, medical and education staff for sharing information [8]. In Qatar, oral health is predisposed by an interchange of socioeconomic, biological, behavioural and political factors $[9,10]$. The momentous interaction between social and behavioural factors has an impact on oral hygiene issue. Interaction between income and education designated as socioeconomic, involving biological factors such as bacterial load presence, simplifies childhood caries, preferably related with socially ruined families [11]. The risk of dental caries generation is highly enhanced by consumption of cariogenic food, the fact directed towards sugary food [12]. Dental caries is also largely associated with dietary habits, for instance, eating too much sugary food responsible for dental caries generation. Eating absurdness is the most occurring cause of dental caries throughout their lives [13]. Oral health has been ignored universally and attracted the less attentive political concern globally, although, this issue is worth discussing, the deficit disorder consequence is that the prevention models implemented is hardly efficient because of political disarrangement [13].

\section{Prevention model implementation}

Four realms constitute the supportive props regarding oral health strategies in Qatar; following up on the dental health model population-wise, the activities involved in prevention arrangement, consistency in workshop arrangement policies and maintaining quality standards. These pillars make more stabilized and sustained health pointing towards the long-term activities targeted towards more efficient activities generation model leading the system to the most robust oral health prevention and promotion at the educational level and the level of population implementation over oral health consistency in Qatar [14]. The approach for prevention activities infrastructure formation is according to the thought of the school of the population with doors wide-opened with diversified opportunities for effective prevention. This approach wrapped around all activated activists including expecting mothers, infants, parents, pre-school children, school children and other individuals such as teachers and school nurses, also those who are suffering from chronic diseases and with common risk factors as oral health disorders. The oral health strategies initiative involved school oral health programmes, to enhance the awareness of preschool and primary school children by early oral caries verification and hence enhanced the scope of treatment with a higher recovery rate.

\section{Significance of workshop organization}

The third domain that interacted in roof sustainability is workshop organization. The number of dentists, oral health care practitioners and oral health hygienists is higher in Qatar, but people are over dependent on refugees. This makes the scene worst when the country is full of sources and resources, but the population is unaware to prevent themselves from oral infections and related disorders. The vast majority of dental care practitioners were available in private sectors rather than in the public sector. The basic theme for organizing a workshop is to re-orientate the system again for individual wellness to heighten the degree of standards in dental practice by increasing self-improvement for locally trained practitioners in Qatar. The condition moving from unawareness to enough awareness is the outcome of any substantially developed or designed workshop. 


\section{Material and Methods}

The approach of the centre stage was adopted to explore the participants' (Table 1) views about what would be the content of the new oral programme, who will be involved, where the challenges and barriers would be when the programme take place and the motivation for the change in their settings [1]. This approach of centre stage was based on Constructivist grounded theory [15]. The constructivist grounded theory differs from Original grounded theory which is grounded by data-guarded theory or data-driven theory highly programmed on researcher's interpretation of data [16], Constructive grounded theory is based on the collaboration of researcher's data and participants' coordination to redesign a theory [15].

\begin{tabular}{|l|c|c|c|c|c|}
\hline S/N & Pseudonym & Gender & Nationality & Age & Description \\
\hline 1 & Mona & Female & Qatari & 34 & Mother of Maria and a Mathematics teacher \\
\hline 2 & Nawal & Female & Qatari & 9 & Grade 4 pupil \\
\hline 3 & Noora & Female & Qatari & 35 & Mother of Nawal and an Administrative employee \\
\hline 5 & Huda & Female & Qatari & 36 & Teacher of Social \\
\hline 6 & Samar & Female & Non-Qatari & 39 & Mathematics teacher for Grade 5 \\
\hline 7 & Sandy & Female & Non-Qatari & 54 & $\begin{array}{c}\text { English teacher for Grade 5 grade and has lived in } \\
\text { Qatar for 15 years. }\end{array}$ \\
\hline 8 & Yahya & Male & Non-Qatari & 38 & $\begin{array}{c}\text { Father of Younus and English, Math, and Science } \\
\text { teacher }\end{array}$ \\
\hline
\end{tabular}

Table 1: Pseudonyms of participants.

The centre stage theory reorganization is based on diagrams used by researchers and data collected from participants' perception accompanied with the related root of association of the research study with the linked phenomenon. The most important link is at the centre of the diagram.

The original plan was to involve 12 participants for the workshop study plan, two potential and forthcoming participants (one each from the private and public schools) were dropped before the workshop organization. Another participant from private school was taken off from the workshop participation due to illness while also from public school another participant declined from joining the workshop due to some family-oriented issues. Thus, a total of eight participants attended the workshop, four from each school. The participants were selected from the case study interviews. The participants involved in workshop experiences have prolonged exposure to educational background. The pseudonyms of all participants recruited in this workshop are listed in the table above

The preliminary arrangements

The workshop participants were provided with notebooks, colouring marker and pen to write their perspective and ideas over the concept of oral health care routine to prevent people from oral infections or caries formation. Each participant was so much energetic and radiant in participating in the activity derived workshop where they were free to talk about their thoughts and interpretations in making the oral care most resilient and easy to adopt. The participants were amazed by experiencing new strategies and life-changing ideas from one another and they were willing to adopt the approach for the wellness of their family and children. The participants went through the information worksheet and the workshop agreement form with other participants again. In this workshop, the participants exchanged ideas, experiences, feelings, suggestions and perceptions towards the awareness and recommended improvement of oral health hygiene in Qatar.

\section{Workshop arrangement}

The aim of the workshop was to explore every low key or inequality circumstances and the prevention strategies that can be implemented widely at an easier pace everywhere. The basic theme behind the workshop organization was to increase consciousness about dental caries, cause associated with these dental infections or tooth destruction highly associated with dental caries 
along with the intervention and prevention models available in getting rid of these ailments. The thrust of the workshop was to design a programme in Dental Caries prevention and the methods or strategies on how to fix this destruction. Through workshop, findings were made based on participants' interviews. The session focused on two steps. The first part of the discussion was on the opinion of individual participants in which the parents were asked what they thought about the oral health issues. This was designated as centre stage in an ideal oral health programme that was guided by diagrams and discussing where, who, what and when in the flowcharts with the important factors at the middle, less important at the margins and looking up for the inter-relationship. This initial step is the basis of designing a model derived from the findings of the interview. The public workshop was conducted in Arabic whereas participants in schools were recruited in English.

\section{Positioning analysis}

The questions have been originated from the case study interviews, similarly, the centre stage diagram (Figure 1) also evaluated the following questions primarily on the same criteria:

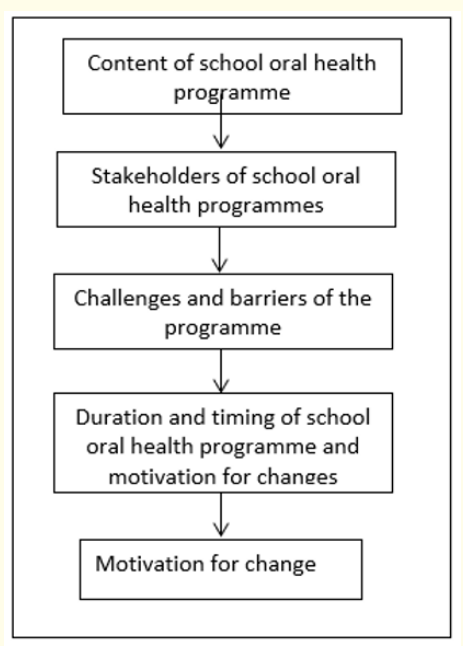

Figure 1: Centre stage diagram.

- What would be the content of the programme, and what would be included?

- Who will be involved in the programme?

- Where are the barriers and challenges to the programme?

- When should different parts of the programme take place?

- In your setting, what would be the primary motivation for change?
The participants discussed each of the questions and then presented the diagram with positioning logistics. This was a prioritybased workshop discussion whose index of contents comprised of school oral health programme, stakeholders of school oral health, challenges and barriers of the programme, duration of school oral health programme and motivation of changes involved.

\section{Results and Discussion}

The finding section consists of dialogues and arguments on behalf of results presented accumulated from parents' perception. The data has been gathered from interviews taken from participants. The theme of the section is to explore results that the researcher has extracted from interviews conducted for parents, nurses, teachers, and pupils themselves. The extracted themes of the workshop are sectioned as follows:

- $\quad$ Content of the oral health programme

- Stakeholders of school oral health programme

- Anticipated challenges and barriers of the programme

- Duration or timing of the school oral health programme

- Motivation for change.

\section{Contents of school oral health programme}

All the participants had evaluated the contents in respective schools' oral health programme to ensure the improvement in oral hygiene in Qatar. Participants were supportive of both the preventive and curative intervention for profound oral health care growth. This oral health care also enhances the schools' preventive interventions in supporting the theme work. One participant shared his view that follow up and monitoring of these health care activities lifted the oral health care to a higher dimension, hence, accelerating the oral health hygiene in school as well as in houses of school-going children. The participants involved in the workshop applauded the role of schools in integrating the oral health care programme at the pre-primary and primary level which was reflected from their dialogues and perspective discussed.

A participant name Samar, introduced as a non-Qatari grade 5 teacher in school stated her point of view as follows:

"I think we need awareness and care because they are different. Awareness is like advising people about health, but care involves providing treatment if there are any issues. This is with regards to the content of the programme". 
The question was raised by one of the participants to indicate the priority of awareness with the incidence of prioritization inspection. One of the questions asked by Samar, a non-Qatari teacher of grade 5 in school stated was:

"So, if we want to identify our priority when it comes to a programme to improve oral habits for school children, what would it be? Do we agree on awareness?"

Organisers of the workshop also concluded that oral health care routine could be assembled or maintained, with consistency, with implementation of early morning catch-up, weekly assembly, workshops organisation, lessons taught on regular basis, distribution of oral health care aids to pupils and direct instructions. Parents' awareness scale upgrading on a community basis is also has an affirmative implication towards the target to be achieved. According to Sandy who is a female English teacher of grade 5 in school, 54 years old non-Qatari participant:

"We have the weekly assemblies where the children usually present plays about lessons they learnt, and we are thinking to incorporate oral hygiene into the lessons and hence these assemblies".

Stakeholders of school oral health project

It was agreed by participants from both private and public schools in Qatar that oral health care was one of the most ignored issues, though not to be, and should be included in regular monitoring of the daily routine. The main stakeholders involved were the schools, family and dental services providers who were involved in school dental health care programme. The opinion expressed by Yahya, a Qatari participant, father of Younis and teacher of English, Maths and Science reflected the theme as stated below:

"Let me tell you about myself. Until today, it is my wife or me who are brushing our children's teeth every morning and evening because if I just tell them to do it on their own, they would do it for few seconds and that's it while it should last for at least a couple of minutes. So, what I believe is that if you are planning to tackle the problem from its roots then you need to involve parents, teachers, and everybody and anybody involved in this process".

The main role in building up and maintaining any habit is played by school efficiently. As a matter of fact, children spent most of their awakening time in schools, they pay more attention to instructions delivered from school sources, therefore, the parents suggested that schools should focus on delivering oral hygiene activities to enhance their spectrum of awareness. This finding is based on the following statement delivered by a participant named Noora who is female administrative employee and mother of Nawal:

"I feel that the bigger role will be for the schools. The school is the main driver for change as it will drive change through the students...it is mainly the schools because the children listen to the advice, they receive at the school more seriously".

Anticipated barriers and challenges in oral health care hygiene

The participants investigated the challenges and barriers to have existed in the research. The participants claimed that teachers' reluctance is the greatest challenge in considering oral health hygiene that can be accomplished only by recreating the mindset of the teachers. According to the teachers, this responsibility will cause increase in their workload. The school authorities should take good care of teachers at this stage if they wish for more friendly interaction among teachers and pupils and they want teachers to be a good counsellor on oral health issues. They should not bother the teachers with extra unnecessary workload. For instance, Samar who is female participant and the teacher of grade 5 elaborated this in the statement below:

"The teachers are already overburdened and hence require some real motivation to take up this additional task...the problem I see lies with the teachers - how do we get involved? ...What do you think? I need all of you to convince me as a teacher to get involved (laughs)".

The participants also agreed that parents should play a role in follow up and regular check-up routines of their children if they are dedicated and willing to control oral infections. The attentiveness in parents' behaviour would play a significant role. Besides teachers and children, the parents should be aware and conscious on an instant and prior basis. The statement of the participant named Samar stated as follows:

"I think that one of the challenges could be non-response from the potential participants, including us (the teachers) and the other reason could be non-response from the students because of their fear of dental problems in general". 
Duration and timings of new school oral health program

A large number of workshop participants added that these kinds of oral health hygiene activities should be carried out throughout the year. They further added that the designed activities should be either daily, weekly, quarterly, biannually or annually administered. For instance, Sandy, a 54 years old female non-Qatari teacher of grade 5 stated as follows:

"The development of awareness should be an ongoing thing throughout the year".

Another participant, Yahya, who is male and father of Nawal elaborated as follows:

"I feel that dental problems are like an epidemic and the majority of the children are suffering from it. That is why I think that one workshop will not bring enough change and we need to have something more".

Another view postulated by Mona who is a female teacher, Qatari and mother of Maria:

"Yes, it could be at least twice a year and involves activities for maybe a week".

Another participant Huda expressed her perspective as follows:

"I think implementation wise the schools are very active in implementing and supporting but the problem is that there is no follow-up post-implementation like assessment, reminders etc".

\section{Motivation for change}

The perception directed towards the change followed by motivation, categories involved were incentives, medical benefits derived from programme, awareness and monitoring. For instance, the participant Yahya, who is male and father of Nawal, stated as follows:

"Coming to the programme, I think there has to be an incentive mainly if the child wasn't taught to do this early in their childhood and asked at older ages. As adults and children, we always need incentives. What do you think?"

Samar, who is female Qatari and mathematics teacher of grade 5 , stated in the statement below:
"As a mother, I will be accepting this programme because it would mean more benefits for my children and fewer dental visits, so this is motivating enough for a parent...It could be the current state of dental health in schools".

To motivate children by diversified oral health routine activities in children's normal oral health care routine. The interaction enhanced at their level by involving them in these kinds of oral health activities and hence the chances increased to prevent the oral infection or tooth destruction.

Design of new school oral health preventing programme

Both primary and private schools have discussed before designing the diagram of the programme. The diagram of the programme designed on mutual agreements of private and public schools is represented below. The centralized idea for the model of the diagram was founded around the information collected from the coproduction workshop and centre-staging or positioning analysis. This subsection based on a co-production discussion of the participants in the public schools and a co-production discussion of the participants in private schools.

Co-production discussion of the participants from the public school

Participant's discussion was directed towards what they were to design. The discussion was at the level of public school. The participants decided to design a diagram with an elaborate network model that describes ideas to follow in the centre stage model in order to construct a final diagram for monitoring and checking up of primary school children dental health care at regular intervals through school and dental clinic visits and parental follow up. The respective diagram is located below.

For instance, Samar, a male participant, and teacher of grade 5, said:

"So now we have 3 sections - content, participants, and challenges. We identified that priority is awareness so what do we discuss next - content or participation?"

“... I think that for such programmes, there should be support from the Ministry of Health as well. It shouldn't be like the initial check-up that we do for creating the student's health record where we wait for hours to see the dentist and itends with a disappointing 
check-up without any result. It is just for the sake of completing the file. But such a programme, if implemented, should have an extension through the ministry such that it starts in the schools, but the followup is done to the clinic and beyond. So, does the Ministry has the ability to provide such support to each school? It seems that awareness and content are interrelated. The content has a direct effect on awareness. What did we discuss about the content? Technical support (Medical teams and follow up)".

Another female participant Noora, who is a mother has stated in a statement:

"Also workshops for the students, parents and the programme managers".

Co-production discussion of the participants from the private school

The participants from private school had a thorough discussion and they directed themselves to work on the flow chart. The organisers of the workshop focused on the same idea that oral health can be every time better than before by implementing dental care strategies delivered via dental care services by school and clinic visits. Each one of the participants agreed on the concept that school and dental care monitoring by parents and dental care clinics are necessary to proposed effective oral hygiene model. The incorporation between school care monitoring system and dental care visits follow-up was targeted to the tremendous result in oral health of primary school children. For instance, an idea shared by one of the organisers of the workshop:

"It all starts from home and then the school and Ministry of Health. The school will follow what is initiated from home to help the child be aware of the importance of oral health. The idea of oral health will be embedded more in the children if they have more access to dental services like check-ups, monitoring, and advertisements about the importance of oral health".

Another participant Yahya commented when the school principal asked question on the dental care services and school interaction. Yahya, father of Nawal commented as follows:

"There will be workshops organized by representatives of the Ministry of Public Health that will be delivered in schools. The responsibility of the school will be daily monitoring of the oral habits for the children, discussing it during events and assemblies and having 3-4 workshops in collaboration with Ministry of Public Health".

The discussion produced the following diagrammatic model in figure.

\section{Synthesis}

This co-production workshop in the public and private schools in Qatar showed the preferences of the organisers on behavioural interventions on oral health issues. The synthesis section comprises the following contents: the content of the school oral health programme, the role of stakeholders in school oral health programme, challenges and barriers of the programme, duration and timings of the school oral health programme, motivation for changes. Participants interacted with their views, ideas, suggestions and also discussed collaborative venture about the preventive and intervention models to put in place.

\section{Conclusion}

The study concluded that to enhance the level of participation in oral health programme, the hurdles and barriers have to be resolved gracefully. Improvement in dental hygiene will automatically correspond with oral health and dental caries prevention in schools [17]. The conducted study has discussed briefly that the implementation of the Health Belief Model in school oral health and dental hygiene is always a world rounder in determining the interrelated barriers and challenges to cope with and the hurdles in designing a new productive image of oral wellness and comfort. Another point of view discussed was that the strategy to diagnose barrier is a good marker in determining the quality relationship between tooth brushing behaviour and prevention of dental caries proportionally in Sisattanak district, Vientiane and beliefs of guardians about oral health behaviour [18]. The prevalence of dental caries is high among school-going children that accounts for approximately $82 \%$ investigated in a study [18]. Tooth brushing behaviour has its importance and it acts as a guard against dental infections and caries generation. Brushing twice a day is also an effective asset and preventive behavioural tool in dental caries generation. The stepwise behavioural progress promoted oral health at a substantial heightened level but the provision of guidance on this health belief model is limited hence the model has been criticized by researchers [19]. The study revealed that the parents, children, 
and dental health care services cooperated to design various work models on which implementation could be easier for everyone and everyone could own or grab it equally at the same pace and intensity. Consistency is the key to success. Schools and teachers could multiply the productive dental preventive output. Workshops organization always enhance performance improvement in the respective category to enhance the efficacies of the oral care hygiene.

\section{Recommendations}

School oral health policy

With several initiatives, participants were engaged in school oral health policies. The role of school in guiding oral health programmes has phenomenon impacts in widening the depth of awareness and stabilizing oral health hygiene together [20]. In the oral health behavioural intervention for children in Qatar schools, school oral health policies need to be improved. The school leadership may provide diets that are low on sugar hence improve the chances of success of the intervention.

\section{Involvement of parents and teachers}

Parents and teacher's involvement in the workshop organization or school guarded health activities is intended to enhance the quality assurance of the programme with respect to their children being enhanced in the awareness level. It has been declared by the researchers who had already conducted the same study in Iran and got success in oral health care initiative [19,21-24]. Parent's efforts are worth praising in following up their children-based health care preventive measure to promote improvement in oral health.

\section{Regulation of children' diet}

To avoid cariogenic and sugary food or to be mindful of children's dietary intake is an accessible tool in raising effective and meaningful dietary patterns in pre-primary and primary schoolgoing children to avoid dental caries and tooth destruction. Parents should take care of their children by building dietary habits which serves in the growth of their children. Qatar is now working on the theme that children are inhibited to carry unhealthy food. Therefore, Qatar is upgraded towards the increased rate of oral health hygiene.

\section{Acknowledgements}

The author wants to thank the primary schools for their participation in the study: Omamah Girls governmental school and Afwaz private school. Also, thanks extend to the parents and students who were the key to this study.

\section{Bibliography}

1. Williams S and Keady J. "Centre stage diagrams: a new method to develop constructivist grounded theory - late-stage Parkinson's disease as a case exemplar". Qualitative Research 12.2 (2012): 218-238.

2. Hashemian M., et al. "Impact of education on interdental cleaning behaviour based on the transtheoretical model". Oral Health and Preventive Dentistry 10.1 (2012): 37-46.

3. Morowatisharifabad M A., et al. "Interdental cleaning behaviour and its relationship with psychological constructs based, on the transtheoretical model". Oral Health and Preventive Dentistry 9.3 (2011): 211-220.

4. Kasila K., et al. "Variation in assessing the need for change of snacking habits in schoolchildren's oral health counselling". International Journal of Paediatric Dentistry 18.2 (2008): 107116.

5. Jin L J., et al. "Global burden of oral diseases: emerging concepts, management and interplay with systemic health". Oral Diseases 22.7 (2016): 609-619.

6. NJ Kassebaum., et al. "Global burden of severe periodontitis in 1990-2010: A systematic review and meta-regression". Journal of Dental Research 93.11 (2014): 1045-1053.

7. Marcenes W., et al. "Global burden of oral conditions in 19902010: a systematic analysis". Journal of Dental Research 92.7 (2013): 592-597.

8. Takeuchi R., et al. "Evaluation of the child oral health promotion "Mali Mali" Programme based on schools in the Kingdom of Tonga”. International Dental Journal 67.4 (2016): 229-237.

9. Tellez M., et al. "Social determinants and oral health: an update". Current Oral Health Reports 1.3 (2014): 148-152.

10. WHO. "Health promotion and oral health" (2018).

11. Gomaa N., et al. "Social- biological interactions in oral disease: A 'cells to society' view'”. PloS One 11.1 (2016): e0146218.

12. Soltani R., et al. "Determinants of oral health behavior among preschool children: Application of the theory of planned behavior". Journal of Dentistry (Shiraz, Iran) 19.4 (2018): 273279.

13. Benzian H., et al. "Political priority of global oral health: an analysis of reasons for international neglect". International Dental Journal 61.3 (2011): 124-130.

14. Ministry of Public Health. "Qatar national oral health: A road map". Doha (2014). 
15. Charmaz K. "Grounded theory: Objectivist and contructivist methods". In The Handbook of Qualitative Research. Edited by N. K. Denzin and Y. Lincoln. Thousand Oaks, CA: Sage Publications, Inc. (2000).

16. Glaser BG and Strauss AL. "The Discovery of grounded theory: strategies for qualitative research". Chicago: Aldine (1967).

17. Rahmati-Najarkolaei F., et al. "'Determinants of dental health behaviors of Iranian students based on the health belief model (HBM)". Shiraz E-Medical Journal 17.7-8 (2016): 1-6.

18. Phanthavong S., et al. "Oral health behavior of children and guardians' beliefs about children's dental caries in Vientiane, Lao People's Democratic Republic (Lao PDR)". Plos One 14.1 (2019): e0211257.

19. Tai BJ., et al. "Assessing the effectiveness of a school-based oral health promotion programme in Yichang City, China". Community Dentistry and Oral Epidemiology 37.5 (2009): 391-398.

20. Kwan SY., et al. "Health-promoting schools: an opportunity for oral health promotion". Bulletin of the World Health Organization 83 (2005): 677-685.

21. Damle S G., et al. "Effectiveness of supervised toothbrushing and oral health education in improving oral hygiene status and practices of urban and rural school children: A comparative study". Journal of International Society of Preventive and Community Dentistry 4.3 (2014): 175-181.

22. Petersen P E., et al. "School-based intervention for improving the oral health of children in Southern Thailand". Community Dental Health 32 (2015): 44-50.

23. Saied-Moallemi Z., et al. "School-based intervention to promote preadolescents' gingival health: a community trial". Community Dentistry and Oral Epidemiology 37.6 (2009): 518-526.

24. Yekaninejad MS., et al. "Effect of a school-based oral healtheducation program on Iranian children: results from a group randomized trial". European Journal of Oral Sciences 120.5 (2012): 429-437.

\section{Assets from publication with us}

- Prompt Acknowledgement after receiving the article

- Thorough Double blinded peer review

- Rapid Publication

- Issue of Publication Certificate

- High visibility of your Published work

Website: www.actascientific.com/

Submit Article: www.actascientific.com/submission.php

Email us: editor@actascientific.com

Contact us: +919182824667 